\section{O ESPORTE NOS ARRABALDES DO RIO DE JANEIRO: 0 CRICKET EM BANGU (1904-1912)}

SPORT IN RIO DE JANEIRO'S OUTSKIRTS: CRICKET IN BANGU (1904-1912)

\author{
EL DEPORTE EN LOS SUBURBIOS DE RIO DE JANEIRO: EL CRICKET EN \\ BANGU (1904-1912)
}

Victor Andrade Melo*, Nei Jorge Santos Junior ${ }^{*}$

\section{Palavras chave:} História do século $X X$.

Brasil.

Esportes.

Críquete.
Resumo: Este estudo teve por objetivo investigar as experiências com o críquete promovidas no Bangu Atlético Clube entre 1904 - data de criação da agremiação - e 1912, último ano em que houve boa movimentação ao redor da prática. Foram utilizadas fontes de duas naturezas: periódicos publicados no Rio de Janeiro no recorte temporal em tela e atas das reuniões da diretoria. Sugere-se que este artigo tem o potencial de ampliar o entendimento sobre: a conformação do esporte na cidade, por abordar uma região ainda pouco investigada; as particularidades do processo de trânsito cultural, por tratar de uma modalidade raramente pesquisada; as estratégias de sociabilidade de um importante grupo social, os britânicos.

Abstract: This study aims to investigate experiences with cricket at the Bangu Atlético Clube between the club's foundation in 1904 and 1912 - the last year when several events related to cricket were held. Two types of sources were used: periodicals published in Rio de Janeiro and minutes of the club's meetings. We suggest that this article may broaden our understanding of: the conformation of sport in the city by addressing an area still little researched; the particularities of the cultural transit process by approaching a sport that has been little researched; strategies of sociability of an important group of foreigners - the British.

\section{Palabras clave:}

Resumen: Este estudio tuvo como objetivo investigar las experiencias con el cricket Historia del siglo XX. Brasil.

Deportes.

Cricket. promovidas en el Bangu Atlético Clube entre 1904 -fecha de creación de esa asociacióny 1912, último año en que hubo un buen movimiento alrededor de esa práctica. Se utilizaron fuentes de dos naturalezas: periódicos publicados en Río de Janeiro en ese recorte temporal y actas de reuniones de la dirección. Sugerimos que este artículo tiene el potencial de ampliar la comprensión sobre: la conformación del deporte en la ciudad, por abordar una región aún poco investigada; las particularidades del proceso de tránsito cultural, al tratar de una modalidad raramente estudiada; las estrategias de sociabilidad de un importante grupo social, los británicos.
*Universidade Federal do Rio de Janeiro. Rio de Janeiro, RJ, Brasil. E-mail: victor.a.melo@uol.com.br

${ }^{* *}$ Faculdade Unilagos. Araruama, RJ, Brasil.

E-mail: edfnei@ hotmail.com

Recebido em: 27-10-2017 Aprovado em: 02-07-2018

DOI: https://doi.org/10.22456/1982-8918.77680 (c) (1) () Licence 


\section{INTRODUÇÃO}

Nos últimos anos, têm sido usualmente investigados os primórdios da conformação do campo esportivo no Brasil, fatos ocorridos na segunda metade do século XIX e primeiras décadas do XX, um momento no qual algumas cidades nacionais passaram por importantes mudanças. Mesmo que a maior parte das pesquisas se refira aos municípios mais importantes e maiores, especialmente às capitais das Províncias/Estados, pode-se dizer já há um bom panorama do assunto. Tais estudos, inclusive, ajudaram a chamar a atenção para a importância histórica da prática'.

A despeito disso, tem sido menos usual a investigação das regiões periféricas das cidades, detendo-se os pesquisadores nas ocorrências das principais agremiações, que normalmente se localizavam nas zonas mais ricas, experiências majoritariamente protagonizadas pelos estratos socioeconomicamente superiores. Quando se trata dos arrabaldes, em geral é abordado o futebol, esporte que, de fato, rapidamente se tornou muito apreciado. São largamente desconhecidos fatos relacionados a outras modalidades que se estruturaram nas zonas suburbanas.

Santos Junior (2017) chama a atenção para os problemas que cercam esse menor conhecimento das áreas periféricas. Um deles é deixar de considerar mais adequadamente os contrastes, conflitos e complexidades da construção dos sentidos de urbanidade. Perdese uma oportunidade de melhor compreender as tensões e peculiaridades do processo de adesão a parâmetros de modernidade que, em muitas ocasiões, vinham do exterior, especialmente do continente europeu, pelo menos até a segunda década do século XX.

Um olhar mais atento a esses outros arranjos citadinos poderia nos permitir entender melhor as particularidades do processo de trânsito cultural, aqui entendido como uma postura ativa de apropriação e ressignificação de bens e representações ${ }^{2}$. Ainda que a conformação do esporte tenha relação com o fato de ser considerado uma civilizada prática estrangeira, não foi somente por isso que, no Brasil, se tornou apreciado, tampouco as distintas modalidades se desenvolveram da mesma forma e no mesmo ritmo.

Trata-se de mais adequadamente encarar a cidade a partir de sua totalidade, percebendo não só o que ocorreu nos arrabaldes, mas também como se estabeleceram os contatos entre o centro e a periferia. Há que se ter em conta que tal relacionamento não se deu da mesma forma em todos os municípios, sendo um desafio captar as particularidades de cada caso.

No Rio de Janeiro, o uso do termo subúrbio sequer se resume a seu sentido etimológico ou geográfico. Não se trata de somente designar uma região afastada do centro. Em muitas ocasiões, representa certa depreciação relacionada à pobreza, precariedade, violência (OLIVEIRA; FERNANDES, 2010), o oposto do que seria a cidade maravilhosa, uma noção que veio se construindo desde o século XIX, teve um importante ponto de inflexão nas reformas urbanas das primeiras décadas do XX e um momento auge nos anos $1950^{3}$.

1 Para um panorama dessas investigações, ver Melo (2010). Para uma crítica ao perfil dos estudos nacionais sobre o tema, ver Dias (2013). 2 Para um debate sobre o assunto, ver Canclini (1997).

3 Sobre a construção da imagem de "cidade maravilhosa", ver Perrota (2011). 
$\mathrm{Na}$ transição dos séculos XIX e XX, aumentou muito o número de habitantes do Rio de Janeiro. Os subúrbios se tornaram - junto com os morros da região central - uma das poucas opções de moradia para a população mais pobre, paulatinamente expulsa daquelas que se configuravam como áreas nobres da cidade (SANTOS, 2011a). Há que se considerar ainda que a ampliação da linha férrea - que começou a ser construída na década de 1850 - facilitou o crescimento de núcleos populacionais nos arrabaldes (FERNANDES, 1995; SANTOS, 2011b). Até mesmo por falta de ação mais clara da administração pública, a ocupação dessas áreas se deu de maneira muito heterogênea, não poucas vezes precária (ABREU, 2011), boa parte graças a iniciativas de empreendimentos privados (MOREIRA, 2013).

Inclusive porque era alto o custo do transporte até o Centro, onde se encontravam os principais postos de trabalho, nem sempre e nem só foram os mais pobres que passaram a viver nos subúrbios. Já que os terrenos eram, em geral, mais baratos, também para lá se mudou gente de estratos intermediários, entre os quais funcionários públicos, profissionais liberais e militares de média patente. Havia ainda os dirigentes de fábricas que foram se instalando na região.

Esse cenário, inclusive no tocante à formação societária, ajuda a entender 0 surgimento de iniciativas de associativismo, entre as quais a criação de agremiações de distintas naturezas que também se estabeleceram como espaços de enfrentamento dos problemas locais e das representações negativas da região, ajudando a forjar uma "identidade suburbana", isto é, discursos mais generosos sobre os arrabaldes.

Entre os diversos bairros do subúrbio do Rio de Janeiro, Bangu é um dos mais simbólicos e representativos. 0 impulso para seu desenvolvimento se deu com a instalação da Companhia Progresso Industrial do Brasil, fábrica do ramo têxtil que tinha em conta aproveitar a linha férrea (graças à ação dos diretores, a primeira estação local foi inaugurada em 18904), a boa disponibilidade de água e o baixo preço dos terrenos. Além disso, em termos relativos, graças ao trem, a localidade não era tão distante da região central ${ }^{5}$.

Até então, era uma zona rural, ponteada de fazendas e plantações ${ }^{6}$. Com a chegada da "Fábrica Bangu", o bairro passou por intensas mudanças, algumas ligadas às ideias de progresso e modernidade tão bem simbolizadas pela nova vocação econômica (FREITAS, 2005; OLIVEIRA, 2006). Durante décadas, a empresa interferiu na vida cotidiana, oferecendo as condições para os trabalhadores se estabelecerem ao redor do parque industrial, também instituindo mecanismos de controle, entre os quais algum grau de intervenção nas agremiações por eles criadas (desde a cessão de espaços, passando pela concessão eventual de auxílios financeiros, chegando até, em alguns casos, a ações mais diretas frente às decisões das diretorias) (SANTOS JUNIOR, 2012; SANTOS JUNIOR, 2017).

\footnotetext{
4 Integrava o ramal, inaugurado em 1878, que ligava Sapopemba (atual Deodoro) a Santa Cruz.

5 Para mais informações sobre as relações entre a Companhia e o bairro, ver Silva (1985).

6 A Fazenda Bangu foi fundada em 1673 pelo negociante português Manoel de Barcelos Domingos.
} 
Figura 1 - Fábrica Bangu, século XIX.

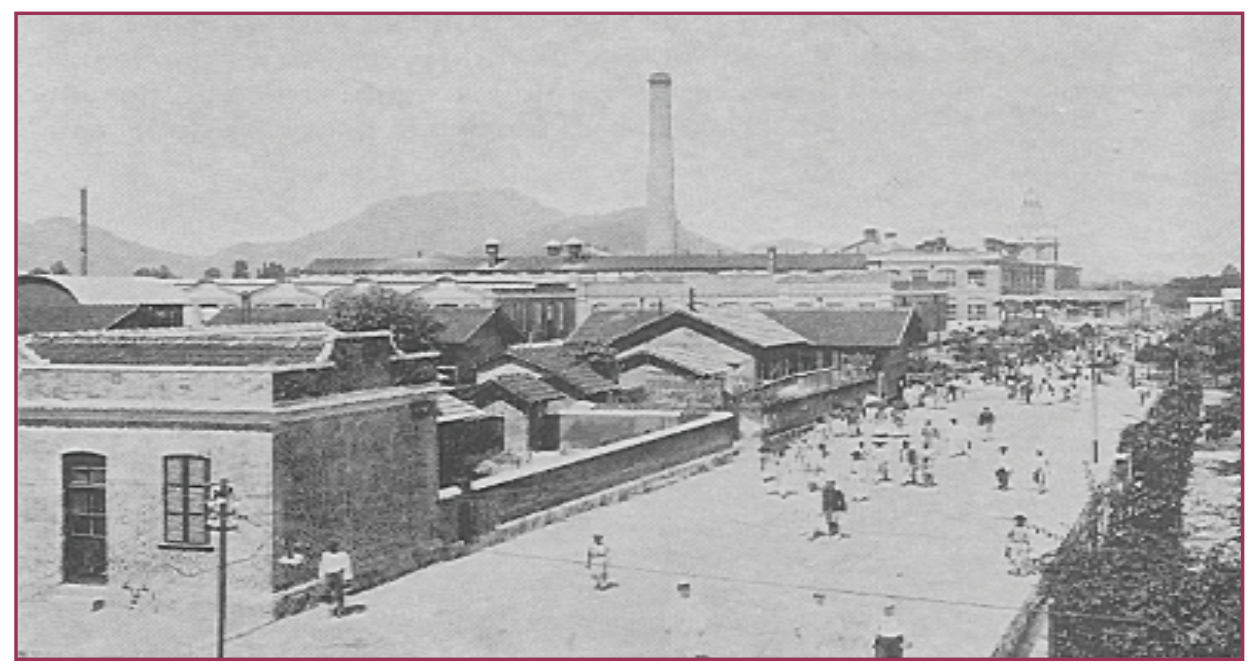

Fonte: Freitas (2005)

Deve-se ter em conta que uma parte dessas iniciativas associativas teve a ver com o fato de que muitos britânicos trabalharam no processo de implantação e funcionamento da Fábrica Bangu. Entre esses, um dos principais artífices foi o engenheiro inglês Morgan Snell, cuja empresa, com sede em Londres, foi a responsável pela construção do parque industrial, adotando o estilo conhecido como "Britânica Manchesteriana", típico das fábricas inglesas (MOLINARI, 2015).

Os britânicos ocuparam um lugar de destaque na economia brasileira desde os anos 1810, algo que se tornou mais notável na segunda metade do século XIX, quando participaram ativamente da instalação de serviços públicos, ferrovias e fábricas (FREYRE, 1977; GRAHAM, 1973; GUIMARÃES, 2012). Em algumas cidades, criaram instituições típicas de seu país de origem: colégios, igrejas anglicanas, cemitérios próprios, agremiações, entre as quais algumas esportivas, que desempenharam importante papel na difusão da prática.

Destaca-se a participação de britânicos nas primeiras experiências do turfe e do remo (MELO, 2001; MELO, 2014; MELO, 2015a; MELO, 2015b), mas também as iniciativas de seus clubes de críquete (MELO, 2017a; MELO, 2017b; MELO, GOMES, 2017), celeiros de outras modalidades, como o rúgbi, atletismo, tênis e, notavelmente, futebol (MELO, 2017c). Em Recife, São Paulo, Santos e Rio de Janeiro, tais agremiações foram instaladas em zonas privilegiadas. Houve uma exceção, o Bangu Atlético Clube, fundado, em 1904, por funcionários da Companhia Progresso Industrial do Brasil.

É verdade que Bangu, em função da monta do investimento e do renome da Fábrica, constantemente recebia gente ligada às elites. Desde sua fundação, em março de 1893, na empresa foram recepcionados políticos, jornalistas e investidores importantes. De outro lado, sempre pendeu sobre o bairro uma série de estigmas que cercavam os subúrbios (SANTOS JUNIOR, 2012).

Dentre os moradores, boa parte de alguma maneira envolvida com a Fábrica, havia aqueles que ocupavam cargos de direção e gerência, entre os quais muitos estrangeiros notadamente britânicos. Mas havia também, em maior número, os operários e outros servidores de camadas populares (alguns originários de outros países). 
Figura 2 - Operários da Companhia Progresso Industrial do Brasil, 1892.

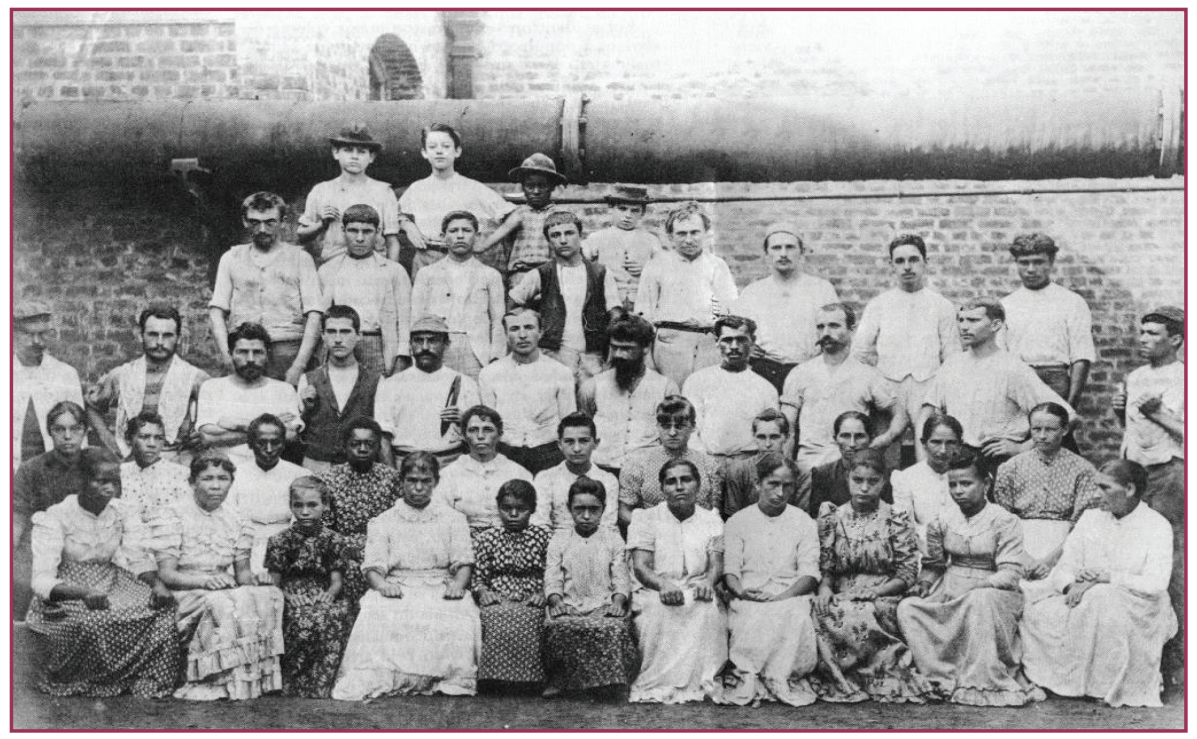

Fonte: Revista Rio de Janeiro, n. 1, dez. 1985.

Quando foi inaugurada, a Fábrica empregava 745 pessoas: 310 homens, 165 meninos, 171 mulheres e 99 meninas. Em 1895, já eram 1.000 (JORNAL DO COMÉRCIO, 29 nov. 1895, p. 3). Em 1899, 1.203 trabalhadores (THE RIO NEWS, 26 dez. 1899, p. 8). Aumentava a cada ano o número de funcionários.

Esse era, em linhas gerais, o potencial quadro social que poderia integrar o Bangu Atlético Clube, agremiação que participou ativamente dos primórdios do futebol no Rio de Janeiro, tema já bastante investigado7. Pouco foi escrito sobre outra prática para a qual foi também criada - o críquete. Escreveu-se na ata de fundação: "Aos 17 de abril, 1904, [...], formou-se um club athletic sob a denominação de "Bangu Athletic Club". [...]. O presidente expôs os fins do club, quais serão os jogos de football, cricket, lawn tennis e outros jogos variados" (BANGU, 17 abr. 1904, p. 1).

Como terão sido as experiências com esse esporte tão importante para os britânicos ${ }^{8}$ ? Elas nos permitem lançar um olhar sobre as relações centro-periferia já que as outras agremiações da modalidade estavam estabelecidas em regiões mais nobres do Rio de Janeiro e Niterói? Sabemos que o Bangu foi um dos pioneiros a incluir gente de estrato socioeconômico mais baixo nos times de futebol (SANTOS JUNIOR, 2012). Isso teria ocorrido com o críquete?

Este estudo teve por objetivo investigar as experiências com o críquete promovidas no Bangu Atlético Clube entre 1904 - data de criação da agremiação - e 1912, último ano em que houve boa movimentação ao redor da prática. Trata-se de uma pesquisa histórica com ênfase no aspecto social.

Foram utilizadas fontes de duas naturezas: periódicos publicados no Rio de Janeiro no recorte temporal em tela e atas das reuniões de diretoria. Para trato dos documentos, teve-se em conta a crítica externa e interna, conforme sugerido por Prost (2008). A abordagem dos jornais e revistas seguiu as orientações de Luca (2005).

7 Para um balanço desses estudos, ver Santos Junior (2012).

8 Para mais informações sobre a importância do críquete para os britânicos, ver: Birley (1999), Malcolm (2012), Burke; Pallares-Burke (2016). 
Sugere-se que este artigo tem o potencial de ampliar o entendimento sobre: a conformação do esporte na cidade, por abordar uma região ainda pouco investigada; as particularidades do processo de trânsito cultural, por tratar de uma modalidade raramente pesquisada; as estratégias de sociabilidade de um importante grupo de estrangeiros, os britânicos.

\section{BANGU ATHLETIC CLUB E O CRICKET}

O Bangu Athletic Club não foi a primeira agremiação fundada no bairro. Durante quase uma década, reinou nos momentos de lazer a Sociedade Musical Progresso, fundada por operários da Fábrica, em 1895, renomeada para Cassino Bangu em 1906, ativa até os dias de hoje.

A essa altura, o associativismo já estava bastante difundido na cidade. Fonseca (2008) sugere que as muitas agremiações fundadas no decorrer do século XIX e anos iniciais do XX desempenharam um importante papel no que tange ao exercício da cidadania num momento em que havia claros limites para tal. Espaços de sociabilidade com certa possibilidade de autorregulação ofereciam oportunidades de vivenciar experiências democráticas tanto no que tange ao seu funcionamento cotidiano quanto no que se refere ao relacionamento com 0 Estado, tendo em conta seus interesses e reivindicações.

Os clubes se estabeleciam como um espaço intermediário entre a vida privada e a vida pública que cada vez mais se delineava como lócus privilegiado de experiências, no qual se gestavam estratégias para fortalecer laços entre diferentes grupos, das mais distintas características. Tinham, assim, uma inegável função política. No caso das agremiações de Bangu, sentiam a influência da Fábrica. De toda forma, gozavam de certa autonomia. Negociações determinavam os caminhos adotados pelas diretorias.

Isso foi claramente sentido no Bangu Atlético Clube. Desde 1897, trabalhadores da Fábrica tentaram criar uma sociedade esportiva (MOLINARI, 2015), mas encararam a resistência do administrador Eduardo Gomes Ferreira. Vale considerar que, anos antes, se envolveram com o críquete alguns dos personagens que atuaram na instalação do parque industrial, como o já citado Mark Sutton, F. Smith, Edward Elkin, entre outros.

Em 1895, o The Rio News, periódico dedicado à colônia de anglófonos estabelecida no Brasil (ROCHA, 2007), noticiou mais um jogo de críquete que se tornara usual nos anos finais do século XIX, disputado entre funcionários de empresas fluminenses - normalmente dirigentes, eventualmente operários, sempre britânicos ${ }^{9}$. A partida entre a equipe da Companhia Progresso Industrial e um combinado das fábricas Aliança, Corcovado e São Cristóvão, acompanhada por grande público, foi saudada, como usual nos eventos da modalidade, como uma oportunidade para celebrar os laços culturais em comum: "o dia foi tudo o que podíamos desejar" (THE RIO NEWS, 28 mai. 1895, p. 8).

Grande parte dos que integraram a equipe não permaneceu por muito tempo no bairro (MOLINARI, 2015). Todavia, vemos pelo menos um nome que depois esteve envolvido com a criação do Bangu Atlético Clube: Donohoe. A iniciativa não chegou a configurar uma agremiação formal e foi bem distinta da que haveria no início do século XX, mas era um indício de que existiam interesses esportivos entre os pioneiros, costume trazido de seu país de origem.

9 Para mais informações sobre esses jogos entre empresas, ver Melo (2017a). 
Somente em 1903, quando a administração da Fábrica passou às mãos do espanhol João Ferrer, criou-se a ambiência necessária para que, no ano seguinte, oito britânicos, um português e um italiano fundassem o Bangu ${ }^{10}$. Ainda que Ferrer tenha sido escolhido presidente honorário, vale destacar que os protagonistas da iniciativa não eram diretores da Fábrica, mas, sim, mestres que ocupavam posição de destaque, inclusive do ponto de vista do conforto financeiro, e se relacionavam mais diretamente com os operários.

Mesmo que adotassem uma postura reservada, os britânicos desempenharam papel importante na difusão do esporte, no caso do Bangu isso pode ter se potencializado pela característica das lideranças. Além disso, a distância da região central da cidade ajuda a explicar o rápido crescimento do número de associados. A maior exigência, que preponderou durante alguns anos, era a vinculação profissional com a Fábrica, podendo ser relativizada pelo bom desempenho em alguma modalidade (SANTOS JUNIOR, 2017). Assim, não surpreende que houvesse maior mistura no que tange à nacionalidade e ao estrato socioeconômico, algo que se notou mais claramente no futebol. Teria ocorrido o mesmo no críquete?

No momento de fundação do Bangu, como primeiro capitão de críquete foi escolhido Thomas Hellowell (BANGU, 17 abr. 1904), inglês de Yorkshire, mestre de fiação, que também atuou como goleiro do time de futebol em algumas ocasiões (MOLINARI, 2015).

Figura 3 - Time de futebol do Bangu'11

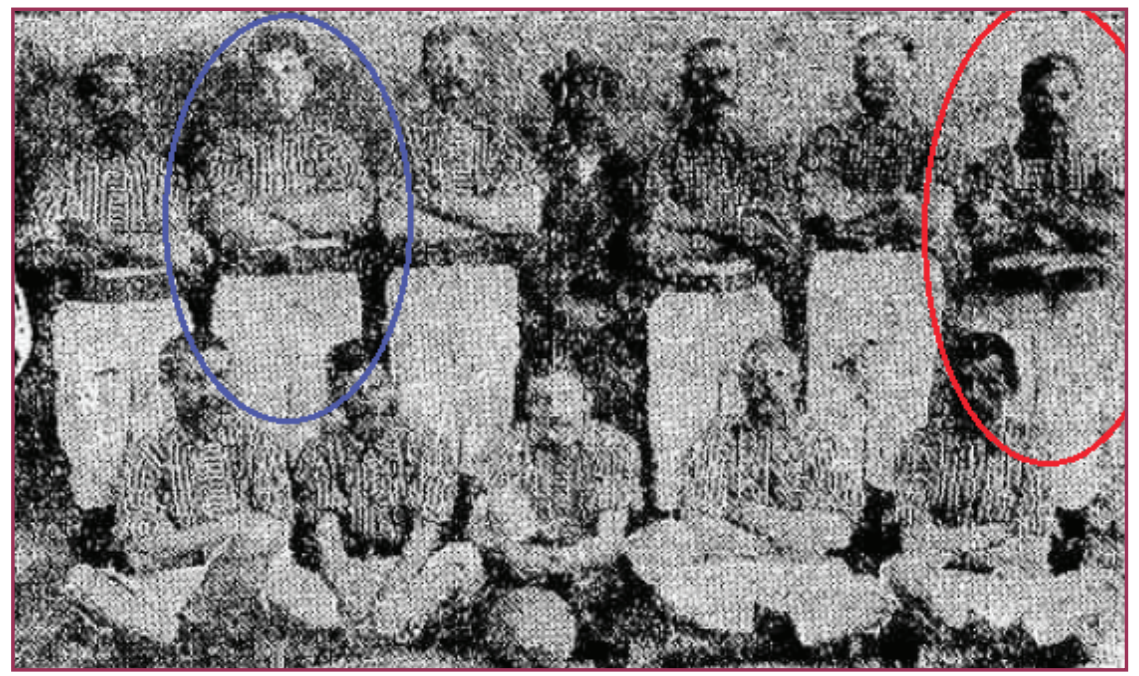

Fonte: DIÁRIO DE NOTÍCIAS, 1932, p.11

Pelo que se pode perceber na segunda ata das reuniões da diretoria, a modalidade deve ter demorado um pouco para ser implementada. Na ocasião, João Ferrer se ofereceu para "concorrer com a quantia que falta para completar a compra dos aparelhos de cricket e lawn tennis" (BANGU, 24 abr. 1904, p. 2). Segundo o documento, o associado Henry Bennet, um dos pioneiros mestres britânicos a atuar na Fábrica, iria adquirir o material numa viagem que faria à Inglaterra.

\footnotetext{
10 Para um perfil dos fundadores do Bangu, ver Molinari (2015).

11 Cotejando com a ata de 20 de julho de 1904 e uma notícia do Jornal do Brasil (31 ago. 1904, p. 3), é possível sugerir que essa seja uma primeiras fotografias do time de futebol do Bangu, anterior àquela que se tornou mais conhecida pela presença de Francisco Carregal, um dos negros a pioneiramente participar de uma equipe fluminense de ludopédio. Publicada no Diário de Notícias (17 abr. 1932, p. 11), por ocasião da comemoração do 28을 aniversário da agremiação, vemos marcado em vermelho Thomas Hellowell e em azul seu filho Guilherme William Hellowell (por vezes confundido com o pai na descrição das imagens do clube). A equipe que enfrentou o Rio Cricket and Athletic Association, em 1904, foi: "Thomas Hellowell, James Hartley e John Stark; Augusto Rosemberg, Clarence Hibbs e William Hellowell; William Procter, José Soares, Thomas Donohoe, Fred. Jacques e Andrew Procter" (JORNAL DO BRASIL, 31 ago. 1904, p. 3).
} 
A primeira referência mais explícita à prática da modalidade se observa em outubro de 1904, quando se resolveu dividir o uso do campo entre o críquete e o futebol, sendo destinado ao primeiro as quartas, sextas e domingos de manhã, enquanto ao ludopédio as segundas, terças, quintas, sábados e domingos à tarde (BANGU, 25 out. 1904, p. 4). Esse é um indício de que havia, nos dois esportes, partidas disputadas entre os associados, organizados espontaneamente ou em times mais estáveis.

Naquele momento, a diretoria continuava tentando conseguir um lugar mais adequado para a prática das modalidades, especialmente para promover partidas com outras agremiações:

Entrou em discussão as obras do terreno novo, sendo resolvido com consentimento do Diretor da Fábrica que o clube levantará a cerca e fará um pavilhão, e que 0 Diretor da Fábrica mandará nivelar o dito terreno, a fim de ficar pronto para os jogos de football e cricket (BANGU, 25 jan. 1905, p. 10).

Em 1906, foi inaugurado o novo campo, num terreno cedido pela Companhia Industrial, localizado na frente da Fábrica, bem perto da estação férrea, onde antes havia uma feira (OLIVEIRA, 2006).

Figura 4 - Campo do Bangu, 1906.

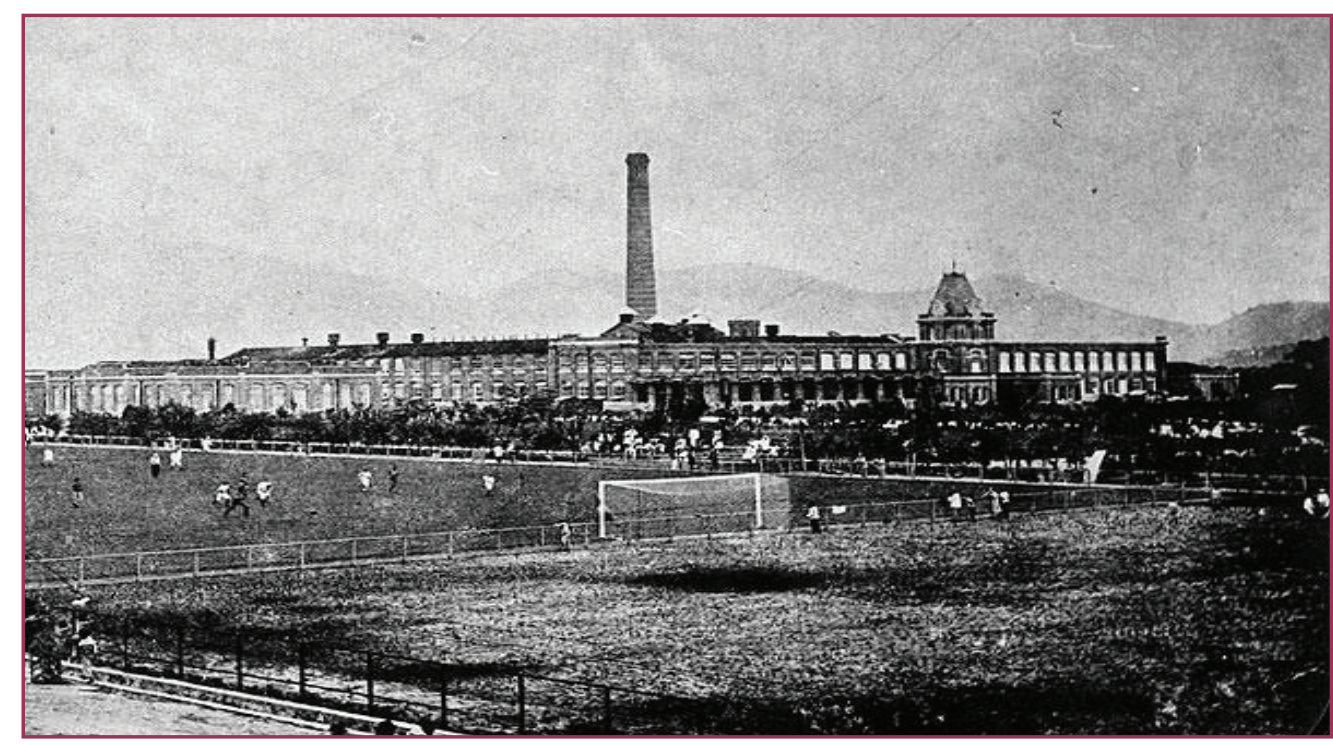

Fonte: Santos Junior (2012).

Nesse campo, que se tornou um dos mais elogiados da cidade, foram jogadas partidas de críquete. Se no século XIX, os espaços esportivos mais bem estruturados eram os dessa modalidade - neles houve várias competições de atletismo, futebol, rúgbi, beisebol (MELO, 2017a) -, no caso do Bangu, a cancha era principalmente destinada ao ludopédio, ainda que acolhesse também outros esportes.

No caso do críquete, o primeiro jogo com outra agremiação parece ter sido disputado contra o Andaraí Futebol Clube $^{12}$, em 1906, dois anos depois do pioneiro certame de futebol. A crer na breve nota, bom público assistiu à pugna dos times formados "quase exclusivamente de laboriosos membros da colônia inglesa" (JORNAL DO BRASIL, 6 fev. 1906, p. 4).

O time do Bangu era integrado somente por britânicos e seus descendentes, entre os quais alguns que atuavam também na equipe de futebol, como William Hellowell, John 
Stark, Thomas Hellowell e Thomas Donohoe (JORNAL DO BRASIL, 6 fev. 1906, p. 4). Isso não era incomum entre membros da colônia, expressão de seu ethos esportivo. Os casos mais conhecidos são os de Charles Miller e Oscar Cox, praticantes de futebol (no qual se notabilizaram), rúgbi, atletismo e até beisebol (MELO, 2017a; MELO, GOMES, 2017; MELO, GONÇALVES, 2018 ${ }^{13}$ ).

Outro importante jogo foi realizado em março de 1907. A princípio, seria disputado com uma equipe de um navio da marinha mercante da Grã-Bretanha. Frente à impossibilidade da tripulação, a partida foi realizada contra o Paissandu Cricket Club (BANGU, 6 mar. 1907; BANGU, 13 mar. 1907; JORNAL DO BRASIL, 9 mar. 1907), agremiação que possuía muitos britânicos como associados e dava sequência à experiência do antigo Rio Cricket Club (MELO, 2017a), ocupando ainda o ground localizado em frente do Palácio Guanabara (bem próximo da sede do Fluminense).

Figura 5 - Ground do Rio Cricket Club/Paissandu Cricket Club ${ }^{14}$.

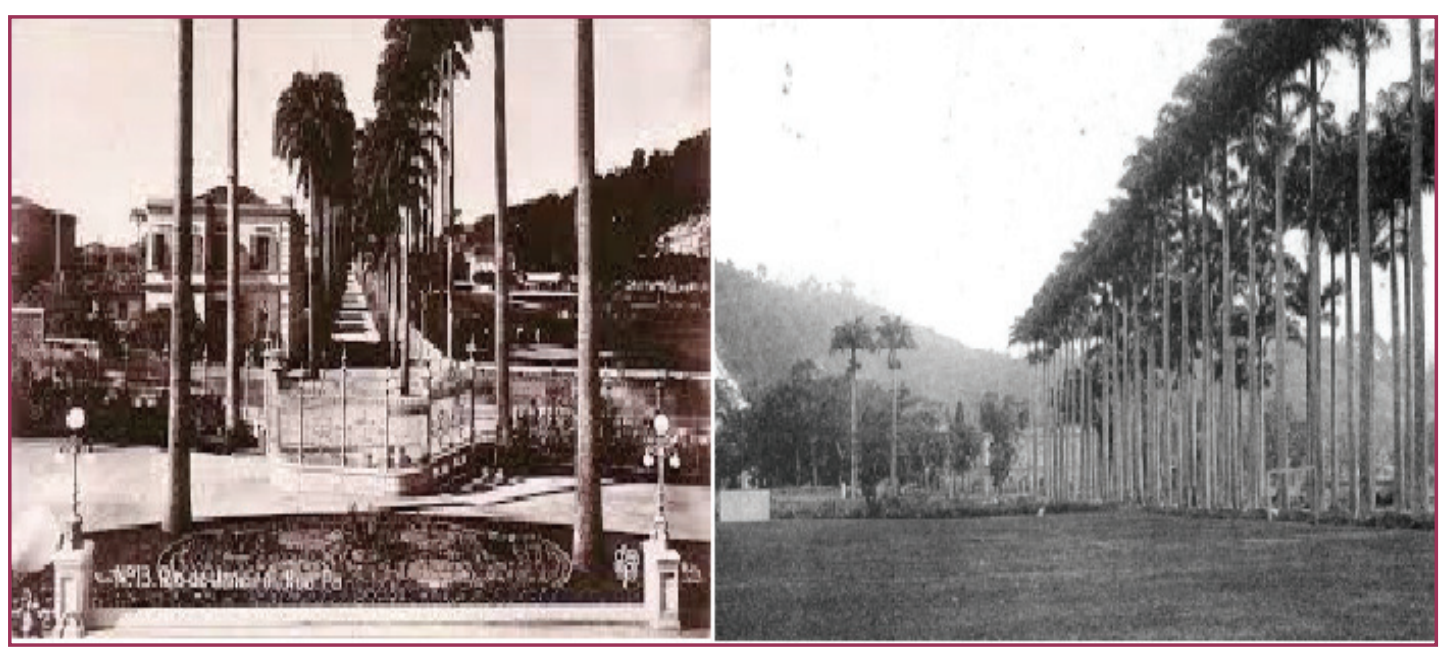

Fonte: https://historiadoesporte.wordpress.com

O rival do Paissandu era o Rio Cricket and Athletic Association (de Niterói), outra agremiação que possuía muitos associados britânicos, com a qual o Bangu com frequência disputou jogos de críquete ${ }^{15}$. Vale destacar uma partida realizada em 1911. A equipe banguense ainda era formada na íntegra por anglófonos, entre os quais Joseph Price (que chegou a ser presidente do clube), Hugh Graham (que se tornou um conhecido árbitro) e os já veteranos Thomas Hellowell e Andrew Procter (escocês, um dos mestres pioneiros da Fábrica, fundador e integrante dos primeiros times de futebol) (JORNAL DO COMÉRCIO, 17 jul. 1911, p. 7). 0 capitão, Charles Barrington Day, era também goleiro (MOLINARI, 2004) ${ }^{16}$.

\footnotetext{
13 MELO, Victor Andrade de; GONÇALVES, Michelle Carreirão. À sombra do futebol: experiências com o rugby nas duas primeiras décadas do século XX. Movimento, 2018. No prelo.

14 Ground do Paissandu Cricket Club, antiga sede do Rio Cricket Club (não confundir com o Rio Cricket and Athletic Club de Niterói). Na primeira imagem (cartão postal da editora F. Manzieri), tomada do Palácio Guanabara, trata-se do terreno da direita, que pode ser visto na outra fotografia em sentido oposto (o Palácio se encontra ao fundo). Disponível em: http:<//cacellain.com.br/blog/?cat=73>.

15 Ver, por exemplo, a ata da reunião de diretoria de 28 de junho de 1910. Com o Rio Cricket and Athletic, o Bangu disputou, em 1904, a primeira partida de futebol.

16 Sobre como o time de críquete do Bangu se manteve só com britânicos, ver também Jornal do Brasil, 27 jun. 1912 , p. 9.
} 
Figura 6 - Equipe do Rio Cricket $^{17}$.

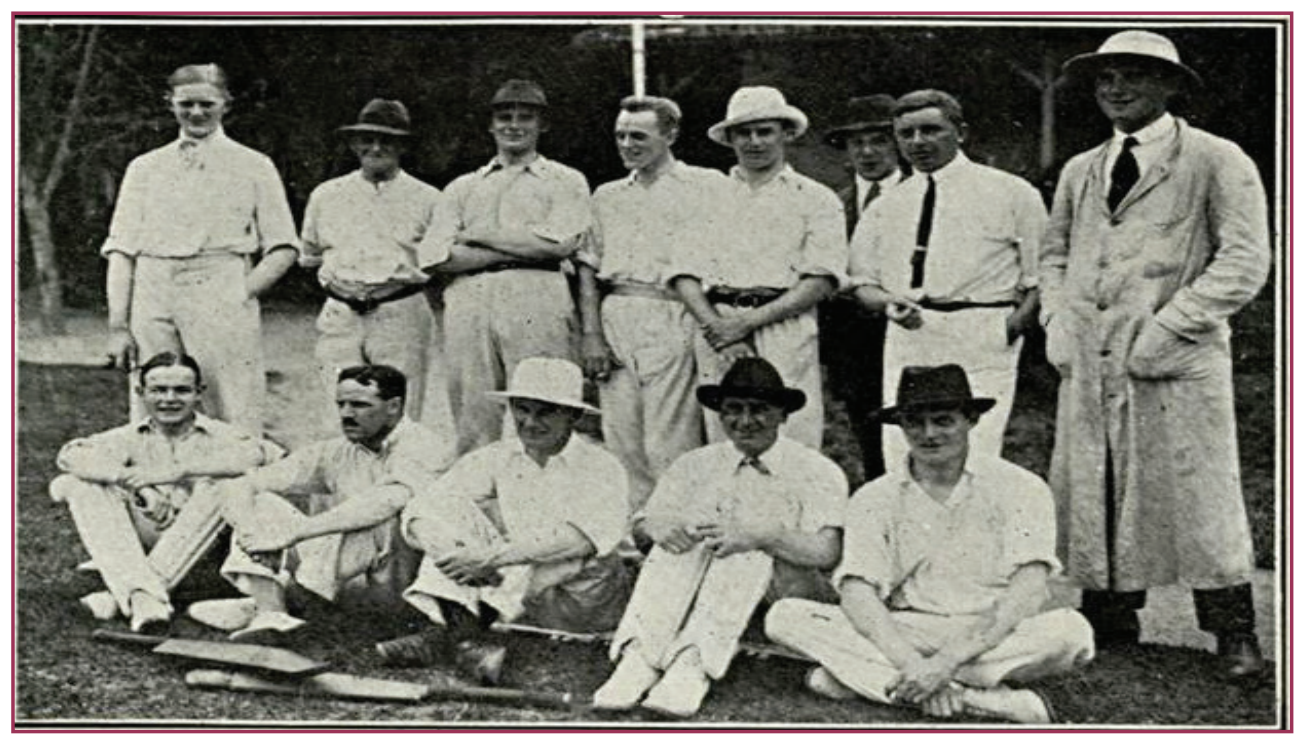

Fonte: Careta, 1913, p. 21.

Vale ter em conta que o Bangu, o Paissandu e o Rio Cricket foram fundadores da Liga Metropolitana de Futebol, criada em 1905, responsável por promover o primeiro campeonato melhor estruturado desse esporte na cidade. Também integrou a iniciativa o Fluminense Futebol Clube, que da mesma maneira possuía equipe de críquete, formada por alguns de seus associados britânicos. As quatro agremiações chegaram a organizar, em 1908, um calendário de jogos da modalidade (O PAIZ, 26 abr. 1908, p. 4).

Nos anos 1900, o campo esportivo já estava bem-estruturado no Rio de Janeiro. As agremiações de britânicos (Paissandu e Rio Cricket) pareciam melhor integradas com as outras da cidade, especialmente por causa do futebol. Todavia, ainda mantinham algumas atividades mais restritas à colônia, como os festivais de atletismo e jogos de críquete, promovidos com certa frequência. $O$ costume de terem um calendário interno anual (ver na próxima página), hábito que vinha do século XIX, não fora abandonado.

O Bangu parece ter se inspirado nessa dinâmica, mas tinha particularidades. Sua equipe de futebol, ao contrário das outras agremiações de britânicos, contava com anglófonos (e seus descendentes) e brasileiros. Já os times de críquete, como os outros da cidade, eram integrados exclusivamente por membros da colônia britânica. 0 clube parecia se constituir como um híbrido das sociedades de anglófonos e aquelas que se estruturaram usualmente nos subúrbios do Rio de Janeiro na primeira década do século XX.

Vejamos que, como era usual nas agremiações de britânicos desde o século XIX (MELO, 2017a), o Bangu promovia jogos de críquete com outros grupos de anglófonos que viviam na cidade $^{18}$, bem como com equipes de embarcações da Grã-Bretanha ancoradas na Baía de Guanabara $^{19}$. Essas ocasiões eram sempre marcadas por celebrações da cultura britânica. O time de futebol, a princípio, até participou de desafios similares ${ }^{20}$, mas isso logo deixou de ocorrer. O ludopédio se tornou popular, pouco restrito, atraindo interesse generalizado.

17 Não conseguimos uma imagem do time do Bangu. Provavelmente se trajavam de maneira semelhante.

$18 \mathrm{Na}$ ata da reunião de diretoria de 31 de maio de 1911, se identifica a preparação para a partida a ser disputada contra uma equipe de britânicos denominada Days XI. Ver também chamada para o jogo contra o time da Rio de Janeiro Literary and Social Union em Jornal do Brasil, 5 set. 1912, p. 8. 
Figura 7 - Calendário do Rio Cricket, $1912^{21}$.

\begin{tabular}{|c|c|c|c|c|c|}
\hline \multicolumn{3}{|c|}{ RIO CRICKET } & \multicolumn{3}{|c|}{$\begin{array}{l}\text { \& ATHLETIC ASSOCIATION FIXTURES } \\
\text { SEASON }-1912 .\end{array}$} \\
\hline \multicolumn{2}{|c|}{ Date } & Game & \multicolumn{2}{|c|}{ FIXTURES } & Ground \\
\hline 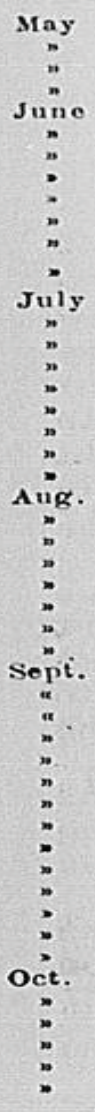 & 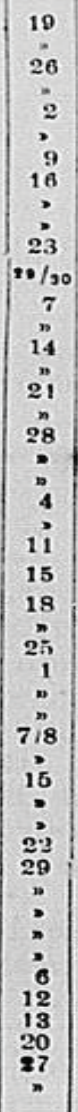 & 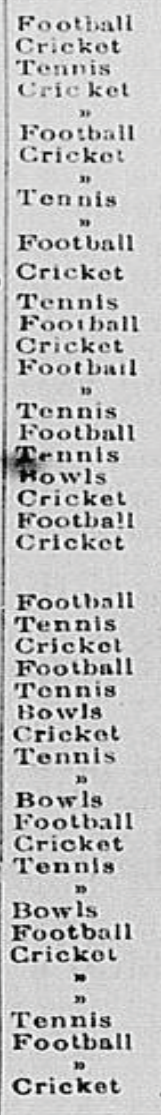 & 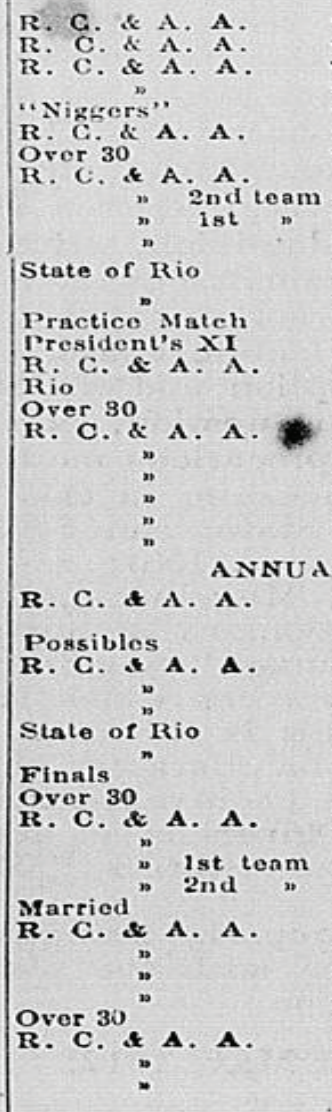 & 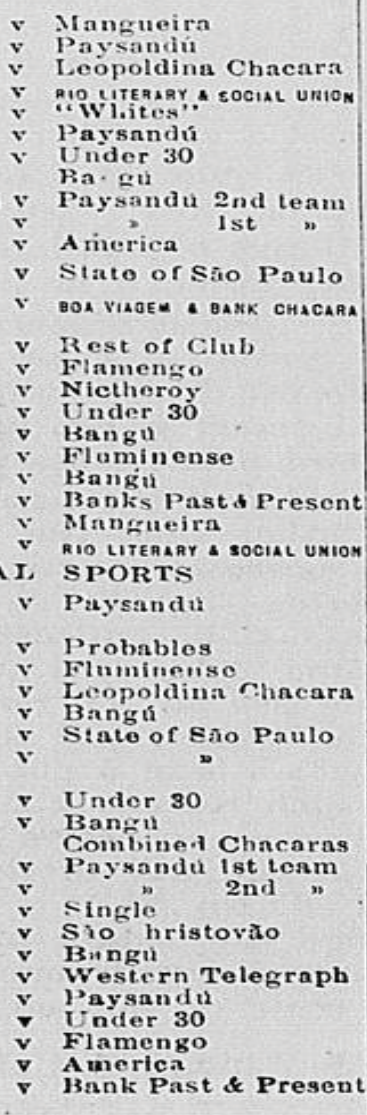 & 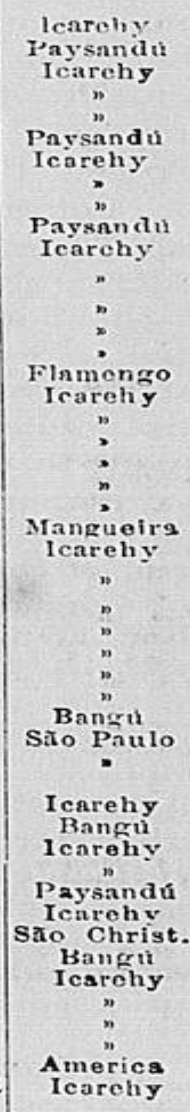 \\
\hline
\end{tabular}

Fonte: The Brazilian Review, 1912, p. 18.

No decorrer dos anos, claramente percebe-se maior investimento e afeição ao futebol, mas o críquete sempre manteve um espaço constante. Na ata de 9 de maio de 1911, que trata de um jogo a ser realizado contra o Andaraí Futebol Clube, especifica-se que somente depois do certame, se houvesse tempo, seriam realizados os treinos de futebol. Informou-se ainda que as iniciativas da modalidade deveriam sempre ter seus dias e horários respeitados.

Em 1912, o Bangu era considerado um "florescente centro esportivo" onde "encontramse bons cricketers" (JORNAL DO BRASIL, 30 jun. 1912, p. 15). Considerava-se que era uma equipe bem-preparada (JORNAL DO BRASIL, 4 jul. 1912, p. 11), que disputava "com bom style matches apreciáveis com equipes mais fortes" (JORNAL DO BRASIL, 11 ago. 1912, p. 16), ainda que nem sempre lograsse vencer ${ }^{22}$.

O críquete, de fato, contribuía para que se elevassem as considerações civilizacionais com o bairro, considerado um sinal de que Bangu progredia e se modernizava. Com o futebol,

21 Perceba-se a regularidade dos jogos de críquete e de outras modalidades em conjunto com as partidas de futebol do campeonato de futebol da Liga também inseridas no calendário. 
ocorria o contrário. Ao seu redor, usualmente se manifestavam os estigmas do subúrbio (SANTOS JUNIOR, 2012).

A despeito de ser relativamente valorizado e manter bom espaço, por motivos que não conseguimos precisar, a partir de 1913 encontramos poucas notícias sobre o críquete no Bangu. Na ata de 2 julho de 1914, há uma informação sobre um jogo contra "um grupo de ingleses residentes no Rio", promovido por Andrew Procter. No mesmo ano, foi marcado "um match de cricket contra a oficialidade e inferiores do Cruzador inglês Glasgow, a consulte destes" (BANGU, 23 jul. 1914, p. 30).

Em 1915, também somente encontramos duas notícias, uma sobre uma disputa contra um "team particular" (BANGU, 23 abr. 19015) e outra ainda mais genérica, deixando claro que somente seguiam envolvidos com a prática os "sócios ingleses" (BANGU, 30 set. 1915, p. 42). Pelos jornais, nada mais foi possível saber.

É provável que seguissem sendo promovidos jogos internos. Há que se considerar também que o críquete esmoreceu na cidade, sumiu dos noticiários, talvez porque tenha se reduzido a colônia britânica no Rio de Janeiro, até mesmo em função da 1a Grande Guerra, algo que inclusive interferiu na participação das suas agremiações nos campeonatos de futebol.

De toda forma, há que se registrar a importante experiência do críquete em Bangu. E o fato de que por lá também definitivamente preponderou o futebol.

\section{CONSIDERAÇÕES FINAIS}

Os estudos sobre as experiências com o críquete desenvolvidas no Rio de Janeiro, São Paulo e Recife demonstram que, mesmo que tenham existido algumas iniciativas com brasileiros envolvidos, foi uma modalidade que não caiu no gosto popular, ficando mais restrita aos britânicos e seus descendentes, um costume que trouxeram de seus país de origem, uma forma de celebrar sua cultura em comum.

As agremiações até então investigadas eram majoritariamente integradas por britânicos de estratos socioeconômicos superiores. $O$ caso do Bangu merece atenção por se tratar de um clube situado numa região mais afastada da cidade, formado por anglófonos e brasileiros, de estrato médio e popular, que interagiam mais usualmente. Os associados tiveram a oportunidade de conhecer dois esportes que se desenvolveram pari passu, o futebol e o críquete.

Se no futebol havia maior convivência e diálogo entre os grupos, o mesmo não se passou no críquete, sempre mais restrito aos britânicos. Mesmo o segundo sendo elogiado como um exemplo de civilização, ao contrário do primeiro, constantemente enquadrado nos estigmas do subúrbio, foi mesmo o ludopédio que caiu no gosto dos associados e se consolidou.

O caso do Bangu, assim, nos permite pensar nos limites do processo de trânsito cultural, refletir como há questões simbólicas e representacionais no desenvolvimento do gosto esportivo, para além de dimensões como a restrição (havia possibilidade de participação) ou desconhecimento (era de conhecimento geral).

Logo, uma ocorrência de uma região periférica ajuda-nos a lançar novos olhares sobre o fenômeno esportivo, reforçando a compreensão de que é necessário investigar a cidade em sua totalidade, entendendo melhor e de forma mais complexa a construção de sentidos de urbanidade. 


\section{REFERÊNCIAS}

ABREU, Maurício de Almeida. A evolução urbana do Rio de Janeiro. Rio de Janeiro: IplanRio/ Zahar, 2011.

BANGU Athletic Club. Livros de atas. Rio de Janeiro: Bangu Athletic Club, 1904-1912.

BIRLEY, Derek. A social history of English cricket. Londres: Aurum, 1999.

THE BRAZILIAN REVIEW, Rio de Janeiro,14 maio 1912, p. 24

BURKE, Peter; PALLARES-BURKE, Maria Lúcia Garcia. Os ingleses. São Paulo: Contexto, 2016.

CANCLINI, Néstor García. Culturas híbridas: estratégias para entrar e sair da modernidade. São Paulo: Edusp, 1997.

CARETA, Rio de Janeiro, 18 out. 1913, p. 21

DIÁRIO DE NOTÍCIAS, Rio de Janeiro, 17 abr. 1932, p. 11.

DIAS, Cleber. Esporte e cidade: balanços e perspectivas. Tempo, v. 17, n. 34, p. 33-44, jan.jun. 2013

FERNANDES, Nelson da Nobrega. 0 rapto ideológico da categoria subúrbio. Rio de Janeiro: UFRJ, 1995.

FONSECA, Vitor Manoel Marques da. No gozo dos direitos civis: associativismo no Rio de Janeiro, 1903-1916. Niterói: Muiraquitã, 2008.

FREITAS, Adriana Oliveira de. Abalou Bangu! A Fábrica Bangu e a república nascente (1889-1914). 2005. 131 f. Dissertação (Mestrado em História Social das Relações Políticas) - Vitória: Universidade Federal do Espírito Santo, 2005.

FREYRE, Gilberto. Ingleses no Brasil. 2. ed. Rio de Janeiro: José Olympio/MEC, 1977.

GRAHAM, Richard. Grã-Bretanha e o início da modernização no Brasil: 1850-1914. São Paulo: Brasiliense, 1973.

GUIMARÃES, Carlos Gabriel. A presença inglesa nas finanças e no comércio no Brasil Imperial: os casos da Sociedade Bancária Mauá, MacGregor \& Cia. (1854-1866) e da firma inglesa Samuel Phillips \& Cia. (1808-1840). São Paulo: Alameda Editorial, 2012.

JORNAL DO BRASIL, Rio de Janeiro, 31 ago. 1904, p. 3

JORNAL DO BRASIL, Rio de Janeiro, 6 fev. 1906, p. 4.

JORNAL DO BRASIL, Rio de Janeiro, 9 mar. 1907, p. 5.

JORNAL DO BRASIL, Rio de Janeiro, 27 jun. 1912, p. 9.

JORNAL DO BRASIL, Rio de Janeiro, 30 jun. 1912, p. 15.

JORNAL DO BRASIL, Rio de Janeiro, 4 jul. 1912, p. 11.

JORNAL DO BRASIL, Rio de Janeiro, 11 ago. 1912, p. 16

JORNAL DO BRASIL, Rio de Janeiro, 5 set. 1912, p. 8. 
JORNAL DO BRASIL, Rio de Janeiro, 29 set. 1912, p. 12.

JORNAL DO COMÉRCIO, Rio de Janeiro, 29 nov. 1895, p. 3

JORNAL DO COMÉRCIO, Rio de Janeiro, 17 jul. 1911, p. 7.

LUCA, Tânia Regina de. História dos, nos e por meio dos periódicos. In: PINSKY, Carla Bassanezi (org.). Fontes históricas. São Paulo: Contexto, 2005. p. 111-153.

MALCOLM, Dominic (Org.). Globalizing cricket: Englishness, empire and identity. Londres: Blomsburry, 2012.

MELO, Victor Andrade de. Cidade sportiva: primórdios do esporte no Rio de Janeiro. Rio de Janeiro: Relume Dumará/Faperj, 2001.

MELO, Victor Andrade (Org.). Os sports e as cidades brasileiras: transição dos séculos XIX e XX. Rio de Janeiro: Apicuri/Faperj, 2010.

MELO, Victor Andrade de. Antes do club: as primeiras experiências esportivas na capital do Im MELO, Victor Andrade. O sport em transição: Rio de Janeiro, 1851-1868. Movimento, v. 21, n. 2, p. 363-376, 2015a.

MELO, Victor Andrade. Entre a elite e o povo: 0 sport no Rio de Janeiro do século XIX (1851-1857). Tempo, v. 20, n. 37, p. 1-22, 2015b.

MELO, Victor Andrade de. A sociabilidade britânica no Rio de Janeiro do século XIX: os clubes de cricket. Almanack, n. 16, p. 168-205, ago. 2017a.

MELO, Victor Andrade de. Para inglês ver? Os clubes de cricket e a sociabilidade britânica em Recife (1865-1906). Territórios e Fronteiras, v. 10, n. 1, p. 161-178, jan.jul. 2017b.

MELO, Victor Andrade de. Evidência e especulação: a "origem" do futebol no Rio de Janeiro (18981902). Movimento, v. 23, n. 3, p. 919-934, jul./set. 2017c.

MELO, Victor Andrade de; GOMES, Eduardo de Souza. Os britânicos e os clubes de cricket na São Paulo do século XIX (anos 1870-1890). Rio de Janeiro, 2017. mimeo.

MOLINARI, Carlos. Mestres estrangeiros; operariado nacional: resistências e derrotas no cotidiano da maior fábrica têxtil do Rio de Janeiro (1890 - 1920). 2016. 259 f. Dissertação (Mestrado em História) - Brasília: Universidade de Brasília, 2015.

MOLINARI, Carlos. Nós que somos banguenses. Rio de Janeiro, Ícone, 2004. (atualizado em 2016). Disponível em: <http://www.bangu.net/informacao/livros/nosequesomosbanguenses/apresentacao. php>. Acesso em: 22 out. 2017.

MOREIRA, Luciana Verônica Silva. Formação do espaço social suburbano no Rio de Janeiro do início do século XX nas páginas do jornal O Subúrbio. Confluências Culturais, v. 2, n. 2, p. 43-55, 2013.

OLIVEIRA, Márcio Piñon de. Quando a fábrica cria o bairro: estratégias do capital industrial e produção do espaço metropolitano no Rio de Janeiro. Scripta Nova - Revista Electrónica de Geografía y Ciencias Sociales, v. 10, n. 218 (51), ago. 2006. Disponível em: <http://www.ub.edul geocrit/sn/sn-218-51.htm>. Acesso em: 23 ago. 2018. carioca. Rio de Janeiro: Lamparina: Faperj/ EdUFF, 2010. 
O PAIZ, Rio de Janeiro, 26 abr. 1908, p. 4.

O PAIZ, Rio de Janeiro, 7 out. 1911, p. 11.

PERROTA, Isabella Vicente. Desenhando um paraíso tropical. A construção do Rio de Janeiro como um destino turístico. Tese (Doutorado em História, Política e Bens Culturais) - Rio de Janeiro: Fundação Getúlio Vargas/RJ, 2011.

PROST, Antoine. Doze lições sobre História. Belo Horizonte: Autentica, 2008.

REVISTA DA SEMANA, 17 set. 1905, p. 22.

REVISTA RIO DE JANEIRO, n. 1, dez. 1985.

THE RIO NEWS, Rio de Janeiro, 28 maio1895, p. 8.

THE RIO NEWS, Rio de Janeiro, 26 dez. 1899, p. 8

ROCHA, Antonio Penalves. The Rio News de A. J. Lamoureux: um jornal abolicionista carioca de um norte-americano. Projeto História, n. 35, p. 141-159, dez. 2007.

SANTOS, Leonardo Soares dos. A constituição do subúrbio na cidade do Rio de Janeiro na virada do século XIX: um passeio pela literatura. Chão Urbano, v. 1, p. 1-17, 2011 .

SANTOS, Leonardo Soares dos. A cidade está chegando: expansão urbana na Zona Rural do Rio de Janeiro (1890-1940). Crítica Histórica, v.2, n. 3, p. 114-137, jul. 2011b.

SANTOS JUNIOR, Nei Jorge. A construção do sentimento local: o futebol nos arrabaldes de Andaraí e Bangu (1914-1923). Dissertação (Mestrado em História Comparada) - Rio de Janeiro: Universidade Federal do Rio de Janeiro, 2012.

SANTOS JUNIOR, Nei Jorge. A vida divertida suburbana: representações, identidades e tensões em um arrabalde chamado Bangu (1895-1929). Tese (Doutorado em Lazer) - Belo Horizonte:

Universidade Federal de Minas Gerais, 2017.

SILVA, Gracilda Alves de Azevedo. Bangu: a fábrica e o bairro. Um estudo histórico (1889-1930). Dissertação (Mestrado em História Social) - Rio de Janeiro: Universidade Federal do Rio de Janeiro, 1985. 
Apoio: 